Int. J. Odontostomat.,

8(2):289-298, 2014.

\title{
Bone Substitutes used in Dentistry
}

\author{
Sustitutos Óseos Utilizados en Odontología
}

\section{Ana Cláudia Rossi*; Alexandre Rodrigues Freire*; Felippe Bevilacqua Prado* \& Paulo Henrique Ferreira Caria*}

ROSSI, A. C; FREIRE, A. R.; PRADO. F. B. \& CARIA. P. H. F. Bone substitutes used in dentistry. Int. J. Odontostomat., 8(2):289-298, 2014.

ABSTRACT: Repair of bone defects resulting from trauma, tumor resections and infections is a medical and dental problem that needs a practical and low cost solution. To facilitate the repair several grafts or bone substitutes may be applied inside the defects. Biomaterials allow treatment, increase or replacement of any tissue, organ or function of the body. The aim of this study was to approach the advantages, disadvantages and main applications of bone substitutes used in reconstruction searched in dental practice. The manuscripts used in this literature review were searched in Medline (PubMed) and Scopus databases and based on manuscripts published from 1991 to 2012. After reading the titles and abstracts of the manuscripts, studies were selected because of their correlations with the aim of the current study. Bone tissue engineering has emerged as a new area of regenerative medicine and biomaterials and has an essential function concerning osteoconductive scaffold, osteogenic growth factors, and osteogenic cells. Based on literature available, a combination of advantageous properties of natural resorbable polymers and bioactive material in nanoscale appears to be more relevant for use in bone defects.

KEY WORDS: biomaterials, bone repair, tissue engineering, dentistry.

\section{INTRODUCTION}

Studies about bone regeneration include not only surgical techniques but also biological and molecular devices. The development of a new medical formulation is based on the understanding of etiology, disease pathogenesis, its progression and the general principles of tissue repair (Pellegrini et al., 2009).

Bone repair is a neoformation process that occurs after trauma or tissue damage (Mindea et al., 2009). One of the main events of this process is the osteoblast differentiation, in which two factors are decisive in this phase: osteoinduction and osteoconduction. Initially, specific growth factors for bone tissue stimulate undifferentiated mesenchymal cells to become pre-osteoblasts (Yamaguchi et al., 2000). Specific transcription factors such as Core binding factor alpha 1 (Cbfa1), translate specific proteins of osteoblasts that associated with growth factors act in the formation of osteoblastic cells (Yamaguchi et al.).
Critical-sized bone defects are commonly caused by trauma, tumor excision, pathological degeneration or oral implants rehabilitation. The resulting bone and soft tissue loss can inhibit normal orthopedic repair by local tissue-based processes. Under those circumstances it is possible to use tissue transplantation or tissue engineering approaches to facilitate bone regeneration and repair. Regeneration of oral and craniofacial tissues presents a great challenge that requires synthesis of basic science, clinical science, and engineering technology (Scheller \& Krebsbach, 2009).

Autogenous bone graft is used for resorption and / or remodeling without antigenic reactions, risks of disease transmission and can be obtained from sources intra or extra-oral (Cancian et al., 1998). However, using this type of graft is not always possible due to some disadvantages or clinical situations such as: defect size, insufficient donor tissue quantity, need 
for second surgical procedure to obtain the graft, donor site morbidity and the need for general anesthesia to obtain extra-oral donor sites (Becker et al., 1998; Cancian et al.). Therefore, limited amount and occurrence of bleeding, infections, and neuralgias of other surgical sites are effects that limit the use of this type of graft (Caria et al., 2007).

Biomaterial is a compound which in contact with human or animal biological system may treat, augment or replace any tissue, organ or even a specific body function (Caria et al.). In order to facilitate and / or promote regeneration, various types of grafts or bone substitutes may be placed within the defects (Lang et al., 2003). Al-Ruhaimi (2001) reported that an ideal bone substitute should possess the following characteristics: biological compatibility to prevent colonization by pathogens, local or cross-infection, be osteogenic, or facilitate the bone cells growth, possess physical and chemical composition similar to natural bone, providing a scaffold for new bone formation, and be resorbable osteotropic (promote bone formation by their chemical or structural composition), serve as source of calcium and phosphorus, microporous and easy handling. For the restoration of human body tissue damaged beyond their natural healing capacity, the external regenerative resources include cells, scaffolds, and growth factors, provided either in combination or as single constituents. It is a primary requisite and a challenge to select the optimum types of cells, scaffold properties, and growth factors combination to reconstruct a specific tissue in its particular weave and function (Zaky \& Cancedda, 2009).

The aim of this study was to approach the advantages, disadvantages and main applications of bone substitute used to reconstruction searched in dental practice.

\section{MATERIAL AND METHOD}

A systematic literature review was conducted on MEDLINE (PubMed) and Scopus databases using the key words biomaterials, bone repair, tissue engineering, and dentistry, and based on manuscripts and books published from 1991 to 2012. After reading the titles and abstracts of the manuscripts, studies were selected because of their correlations with the aim of the current study.

\section{RESULTS AND DISCUSSION}

Bioactive Glasses. The mechanisms involved in the bioactivity of the bioactive glasses are: a) Process of ionic diffusion of glass; b) Processing within a hydrated gel; c) Counter diffusion of the extracellular matrix toward the glass surface, d) calcium phosphate precipitation in glass (Gatti \& Zaffe, 1991).

Bioactive glass is a bioactive glass-ceramic composed of silicon dioxide/silica ( $\mathrm{SiO} 2$ ), sodium oxide $(\mathrm{Na} 2 \mathrm{O})$, calcium oxide $(\mathrm{CaO})$, and phosphorous (P2O5). The material is biocompatible and degrades by dissolving or resorbing in the body. Bioactive glass has been reported to bond to soft or hard tissues enhance multipotent bone marrow stromal cell function increase bone turn over promote osteogenesis and enhance angiogenesis (Giannoudis et al., 2008). The composition of this biomaterial showed a better response by binding to bone (Hench, 2006).

Besides being highly biological osteoconductive, bioactive glass particles have properties of bone stimulation. This stimulatory effect represents an internal erosion of bioactive glass particles, in which bone formation can be observed separately from external bone (Schepers et al., 1993). Undifferentiated mesenchymal cells penetrate the eroded glass particles and are stimulated by internal ambient into differentiated osteoblasts. These neoformed bone tissue acted as nucleation areas for subsequent bone repair (Schepers et al., 1991, 1993).

The potential of bone formation and mechanical strength of bioactive glass were tested in several animals and in vitro studies, demonstrating the promising potential as bone substitute, since it has biocompatibility and with osteoconductive and bioactive properties (Schepers et al., 1991; Wheeler et al., 1998).

During bone formation, the stage of mineralization is crucial for achieving tissue resistance and therefore to the better neoformed bone quality. Thus, the availability of calcium and phosphate and its incorporation process for organic matrix are primary events that occur in the process of bone regeneration in a satisfactory manner (Mindea et al.).

Some studies have classified as bioactive glasses only bio-inert materials, absence of toxicity and undesirable reactions to the body, however, precipitation of calcium around the particles suggested that in addition to being biocompatible, the material 
presented biological osteoconductive properties, capable of provide an environment conducive to adhesion, bone cells proliferation and growth factors, interacting with surrounding tissues (Gatti \& Zaffe; Schepers et al., 1993; Tadjoedin et al., 2000).

Clinically, bioactive glass presents the main advantages to be a synthetic absorbable and does not require a second surgical procedure. This biomaterial presents no risk of disease transmission or immune responses and aid in hemostasis when applied to bone defects (Gatti et al., 2006).

The main disadvantage of bioactive glass is the tendency to migrate into the surrounding tissue. In limited areas, particles can be compressed and remain united, however, in large defects becomes difficult to keep them in position. The migration of particles can degrade surrounding tissue in contact with surface and lead to an intense inflammatory reaction. The insertion of a resorbable material layer on the particles, keeping them in defect or mixing them with a material that causes their aggregation are two options mentioned by these authors in order to prevent the migrating of particles to the adjacent tissues (Moreira-Gonzalez et al., 2005).

Factors such as method for preparation, composition, and particles size affect the bioactive glass characteristics and its bioactivity (Koleganova et al., 2006; Jones et al., 2006). Bosetti \& Cannas (2005) tested, in a randomized study, three different compositions of bioactive glasses (45S5, $58 \mathrm{~S}$ and $77 \mathrm{~S}$ ) associated with rats bone marrow cells investigating in vitro the influence of glass to induce osteogenic differentiation and bone mineralization, showed that compounds $45 \mathrm{~S} 5$ and $77 \mathrm{~S}$ presented the best results.

In vitro studies have demonstrated the osteogenic effect of bioactive glass biomedically modified, which acted by stimulating and increasing the speed of differentiation of osteoprogenitor cells into functional osteoblasts, as evidenced by increased levels of alkaline phosphatase levels (Radin et al., 2005). Other studies randomized showed that there is glass on apatite-layer formation, rich in calcium and phosphorus, similar to natural bone, that favoring lead bone-glass (Stavropoulos et al., 2003) and inducing colonization of bone cells (Gatti et al., 2006). Bioactive glasses have been associated with other compounds such as demineralized bovine bone (Stavropoulos et al.), autogenous bone graft (Tadjoedin et al., 2000, 2002; Moreira-Gonzalez et al.), calcium phosphate
(Moon et al., 2006), enamel matrix derivative (Kuru et al., 2006), and resorbable polymers composed of lactic acid and glycolic acid (Lu et al., 2003; Leach et al., 2006). Oonish et al. (2000) studied, in animals, bioactive glass, Glass-ceramic A-W and synthetic hydroxyapatite and concluded that bioactive glass showed the highest bone formation rates and degradation, suggesting bone formation rates is proportional to particles dissolution, which favor the osteoblastics action. The authors suggested that probable origin of new bone formation occurs at the periphery of the defect and directly from the glass particles.

Studies about osteogenic capacity of bioactive glass presented diverging results, and suggested that bioactive glass alone does not promote osteogenesis, requiring association with autogenous grafts or cultured cells, demonstrating that material bioactivity is limited and should not be used for filling extensive craniofacial defects (Moreira-Gonzalez et al.).

The clinical applicability of bioactive glass was studied in several clinical and animals studies indicating its use as filling material for maxillary sinus lifting procedures (Tadjoedin et al., 2000, 2002; Cardioli et al., 2001) in order to preserve the quantity of neoformed bone in alveolus after tooth extraction (Teófilo et al., 2004), defects or dehiscence (Cancian et al.), in implants after extractions, aiding in implant stability, and periodontal bone defects (Schepers et al., 1993; Villaça et al. 2005).

Cell culture studies have shown improved bioactivity and biocompatibility in polymer/bioactive glass composites compared to polymer alone. Bioactive glass incorporation increased osteoblasts infiltration of porous polymer scaffold (i.e., cell migration and colonization of deeper scaffold regions), and indicated facilitation of osteoblasts attachment, distribution, and viability. This was further reflected by rapid formation of apatite and cellular attachment in samples containing bioglass. Thus, bioactive glasses are attractive materials for bone tissue engineering, with additional potential for controlling the resorption rates by modify the chemical composition (Tadjoedin et al., 2002).

Polymers derived from polylactic acid and polyglycolic and copolymers. Polymers derived from polylactic acid (PLA) and polyglycolic (PGA) and copolymers exhibited mechanical properties, low allergenic potential, low toxicity, easy handling, 
biocompatibility and predictable degradation kinetics, which aroused the attention of many researchers in medical field (Fialho et al., 2003; Yao et al., 2005).

Highly porous structure of PLA / PGA allows performing the function of acting as a temporary scaffold when used in bone defects enabling cells infiltration and blood vessels around tissues, concomitant with process of degradation and replacement by regenerated tissue (Yao et al.). Due to this biological behavior, research has suggested that this biomaterial presents osteoconductive properties, performing as scaffold for replacement of extracellular matrix (Imbronito et al., 2005; Rimondini et al., 2005).

Although PLA / PGA is a clinical biomaterial indicated in tissue engineering, some characteristics such as low mechanical strength, porosity and hydrophobic properties surface may limit their use. However, surface treatment using natural materials or associations of other substances can facilitate the adhesion, proliferation and osteoblastic differentiation (Wu et al., 2006).

Freire et al. (2012), evaluated the association of the combination of polylactic / polyglycolic acid around implants installed with and without primary stability through the histometric analysis of boneimplant interface in male rabbits, each of which received 2 titanium implants in each tibial metaphysis. The animals were divided into 4 groups: control with primary stability, control without primary stability, polymer with primary stability, and polymer without primary stability. Euthanasia was performed at postoperative days 40 and 90 . These authors found that there was new bone formation in all groups and during all periods by histometric analysis and concluded the copolymer had biocompatibility, enhanced bone healing, and presented osteoconductive properties, thus raising the contact between bone and implant, even without primary stability.

Thus, these biomaterials can be used alone or in association in clinical practice, such fixtures (Kiely et al., 2006), membranes (Hämmerle \& Lang, 2001), solid/ porous graft, possible application as a vehicle for drugs, shippers of growth factors, bone morphogenetic proteins or adhesion proteins (Fialho et al.; Saito et al., 2003; Imbronito et al.; Yao et al.).

Studies have shown that the incorporation of bioactive glass to the PLA / PGA resulted in formation of a structure capable of acting as a scaffold that support the new bone deposition and its vascularization, allowing the proliferation and differentiation of osteoprogenitor cells into osteoblasts (Boccaccini et al., 2003; Yao et al.). The possibility of formation of resorbable compounds with bioactive properties, controlling the speed of degradation, biocompatibility and mechanical properties and structural conditions, are advantages that justify the association between PLA / PGA copolymer and bioactive glass (Lu et al.).

Yao et al. demonstrated that the incorporation of bioactive glass to the copolymer increased the reactivity of the polymer surface and promoted the transformation of its surface into a bioactive layer rich in calcium and phosphate ions (calcium phosphate layer). After 2 weeks of immersion, the microparticles of calcium and phosphate were formed in the composites, facilitating the adhesion and cell differentiation.

Rimondini et al., analyzed the bone repair after copolymer of PLA / PGA implantation in the ratio 50/50, used as bone substitute and concluded that this copolymer dispersed in hydrosoluble matrix acted as osteoconductive critical bone defects.

Thus, studies have shown beneficial effects of these copolymers in animals and humans (Carmagnola et al., 2003; Holy et al., 2003; Lu et al.; Serino et al., 2003; Nair \& Schug, 2004), highlighting the osteoconductive properties, since they function as a scaffold for replacement of extracellular matrix (Imbronito et al.; Rimondini et al.). These scaffolds, based on alpha-hydroxy acids and usually composed of polyglycolic acid, poly-L-lactic acid, or combination of both, i.e., PLGA, possess limited osteoconductive capacity. However, when combined with hydroxyapatite, they become excellent materials for bone repair, not only for enhancing cell adhesion, but also for inducing osteoprogenitor cells differentiation (Zaky \& Cancedda).

Synthetic calcium hydroxyapatite. Natural based polymers offer the advantage of being similar to biological macromolecules, and thus the biological environment is better prepared to recognize and deal with these polymers metabolically. Because of their similarity to the extracellular matrix, natural polymers may also prevent chronic inflammation or immunological reactions and toxicity, which often occur with synthetic polymers (Mano et al., 2007). When compared with synthetic materials, natural polymers have the advantage of innate environmental 
responsiveness and the ability to be degraded and remodeled by cell-secreted enzymes. They are nontoxic at both low and high concentrations, are readily incorporated into oral or bolus matrix delivery systems, and can serve as tissue engineering scaffolds (Scheller \& Krebsbach).

Natural polymers often possess highly organized structures which can guide cells to grow at various stages of development; they may stimulate an immune response at the same time. Several natural polymers have been reported for applications in bone tissue engineering (Jayakumar et al., 2010).

Hydroxyapatite (Ca10(PO4)6(OH)2) is the most significant inorganic component present in natural bone and has been used as orthopedic and dental material, a column packing material for chromatography affinity to separate various proteins, and in industrial catalysts (Fujii et al., 2006).

Osteoconductivity is another essential requirement of bone-engineering scaffold. The term delineates a bone-growth supporting microenvironment permitting the construct to integrate with the mass bone. It is widely agreed that this property is provided by a mineralized material, which calcium hydroxyapatite and other calcium-phosphate-based minerals are of major interest (Zaky \& Cancedda). Hydroxyapatite has regularly been proposed as a potential synthetic graft material with osteoconductive properties (Talal et al., 2009).

Ishida et al. (1996) proposed a new experimental graft model composed by vascularized periosteal flap from tibia and synthetic calcium hydroxyapatite. These alloplastic grafts ceramic biomaterials, especially the synthetic ones made of synthetic calcium hydroxyapatite have been of major interest by biocompatible and osteoconductors properties, and by offer resistance and stability to fill bone defects. In addition, they are malleable and can be made to fit desired volume and shape (Rosen et al., 1997).

Synthetic calcium hydroxyapatite biocompatibility with bone is due to similarity of the crystal structure. Although widely used, this biomaterial does not have satisfactory osteoinduction properties, but is considered an effective osteoconductive material (Tang et al., 2008).

Tang et al. showed that natural hydroxyapatite associated with chitosan composites have a excellent hard tissue biocompatibility and osteoconductivity. These authors also suggested that this composite may be suitable for artificial bone implants and tissue engineering.

Thus, synthetic calcium hydroxyapatite is one of the ideal materials for bone substitutions due to biocompatibility and mechanical strength nature. Other calcium phosphate apatites including sintered synthetic calcium hydroxyapatite have been widely used for repair and replacement of damaged or traumatized bone tissues (Woo et al., 2007).

Nanocomposite biodegradable polymer. Scientists in tissue engineering have turned to nanotechnology, specifically nanofibers, as the solution to the development of tissue engineering scaffolds for application in tissue repair. At present, only a few processing techniques can successfully produce fibers, and subsequent scaffolds on nanoscale (Jayaraman et al., 2004)

Recently, electrospinning process and nanofibrous matrices manufactured have gained tremendous interest, mainly due to the structural similarity with tissue extracellular matrix, processing availability to a wide range of materials, as well as simple set-up and operation at low cost (Smith \& Ma, 2004). Studies have reported the performance of nanofibrous materials in guiding cells to initially adhere to and spread over the material, as well as further triggering them to secrete the appropriate tissue extracellular matrix molecules targeted to the skin, blood vessel, cartilage, muscle, adipose, nerve and bone (Sill \& von Recum, 2008).

Nanocomposite fibers are of potential interest for bone tissue engineering applications. In bone reconstruction area, electrospun nanofibers have attracted considerable attention aimed at identifying suitable material compositions and exploiting them into electrospinning. As the bone associated cells and their progenitor/stem cells show initial responses in a similar manner to those in other tissues, which are anchorage-dependent, the nanofibrous substratum may provide favorable conditions for cell anchorage and growth. In tandem with the initial cell responses, further osteoblastic differentiation and mineralization have also been reported to be regulated in a positive manner on nanofibrous surfaces compared to dense substrate of polymers (Sill \& von Recum).

The components of bone possess a nanocomposite structure interwoven in a tridimensional 
matrix. In recent years, there was a development of nanomaterials for bone tissue engineering applicability. Natural bone is a complex inorganic/organic nanocomposite material, hydroxyapatite nanocrystallites and collagen fibrils organized in a hierarchical architecture overall several length scales including nanoscale. Polymers can serve as a matrix to support cell growth by present various properties (e.g., biocompatibility, biodegradability, porosity, charge, mechanical strength, hydrophobocity, etc.) that can be easily modified by changing the constituents of monomers in different ratios and controllingpolymerization conditions (Zhang et al., 2008).

The inclusion of nanoparticles into the biopolymer matrix has the dual objective of improving the mechanical properties as well as incorporating nanotopographic features that mimic the nanostructure of natural bone. Thus, the main way of getting artificial biomaterials as bone substitutes in biomines inspired approaches is to produce nanocrystallites of calcium phosphate salt with natural polymers like collagen (Cai et al., 2009).

Yoshida et al. (2006), synthesized composites from cellulose and carbonate hydroxyapatite in situ through mechanochemical reaction. The composites formed calcium phosphate on their surfaces indicated that they have bioactive potential. A composite material consisting of calcium-deficient hydroxyapatite biomimetically deposited in a bacterial cellulose hydrogel has been reported68. The authors showed that bacterial cellulose can be used as template for biomimetic apatite formation and this composite may have potential use as orthopedic biomaterial.

Nanocomposite containing calcined hydroxyapatite nanoparticles is both biocompatible and osteocompatible. From the biomimetic point of view, calcium hydroxyapatite composites could potentially improve both biocompatibility and mechanical properties of bone grafting materials (Jayabalan et al., 2010).

Kashiwazaki et al. (2009), fabricated novel chitosan/hydroxyapatite nanocomposites with porous structure by co-precipitation and porogen leaching method. These composites were found to have biocompatibility and biodegradation.

Osathanon et al. (2008), developed composite scaffolds by deposition of calcium phosphate solution on fibrin surfaces or direct incorporation of nanocrystalline hydroxyapatite. These scaffolds promoted bone formation in a mouse calvaria defect model and increased bone formation by addition of recombinant bone morphogenetic protein-2 (rhBMP-2).

RAD16-I ( $R$, arginine; A, alanine; $D$, aspartic acid) has been frequently used to culture cells in laboratory by its nanostructural and biomechanical properties. Amino acid composition makes it very stable in water solutions as well as easy to synthesize (Semino, 2008). When desired, it can be easily turned into gels by an increase in physiological solutions or $\mathrm{pH}$ adjustment to neutrality. Also, cells can be easily encapsulated into nanofiber network in a truly threedimensional environment. For these reasons, this class of biomaterial scaffold has often been used to promote growth and proliferation of a variety of cell types, including chondrocytes, hepatocytes, endothelial cells, osteoblasts, and neuronal cells, as well as embryonic and somatic stem cells. Homogeneous bone formation was histologically observed through hybrid scaffold, confirming that procedure the RAD16-I could be used to improve bone regeneration (Semino, 2008).

\section{CONCLUSIONS}

A significant amount of research has been directed to electrospinning nanofibrous materials targeted for bone regeneration. The selection of materials with the appropriate composition is of utmost importance in the successful generation of bone tissue extracellular matrix mimicking matrices suitable for neobone formation.

Since the inception of tissue engineering field, many methods have evolved from the simple concept of placing cells in a degradable scaffold to building native tissues either in vivo or in vitro. Ultimately, engineers must match applications, materials, and fabrication processes to best meet the needs of tissue they wish to build. It is anticipated that nanotechnology will be a key component in development of next generation of scaffolds, particularly with respect to the fabrication component.

Alternative strategies for bone tissue engineering have been developed involving three components: osteoconductive scaffold, osteogenic growth factors, and osteogenic cells. Bone tissue engineering has 
emerged as a new area of regenerative medicine and biomaterials have an essential function concerning celladhesion, spreading, proliferation, differentiation and tissue formation in three dimensions. Based on this literature review, a combination of the advantageous properties of natural resorbable polymers and bioactive material in nanoscale appears to be more relevant for use in bone defects/bone regeneration.

ROSSI, A. C; FREIRE, A. R.; PRADO. F. B. \& CARIA. P. H. F. Sustitutos óseos utilizados enodontologia. Int. J. Odontostomat., 8(2):289-298, 2014.

RESUMEN: La reparación de defectos óseos que resultan de traumas, resección de tumores e infecciones son un problema médico y dental que necesitan una solución práctica y de bajo costo. Para facilitar la reparación, diversos injertos o sustitutos óseos pueden ser aplicados en el interior de los defectos. Los biomateriales permiten tratar, aumentar o sustituir algún tejido, órgano o función del cuerpo. El objetivo de este estudio fue acercarse a las ventajas, desventajas y principales aplicaciones de los sustitutos óseos utilizados para la reconstrucción en la práctica dental. Los manuscritos utilizados en esta revisión sistemática de la literatura se realizaron mediante la búsquedas en Medline (PubMed) y bases de datos Scopus, basada en manuscritos aparecidas entre 1991 y 2012. Después de leer los títulos y resúmenes de los manuscritos, los estudios fueron seleccionados debido a su correlación con el objetivo del presente estudio. Ingeniería de tejido óseo se ha convertido en una nueva área de la medicina regenerativa y biomateriales y tiene una función esencial en relación osteoconductivo andamio, factores de crecimiento osteogénicos, y las células osteogénicas. Basado en la literatura disponible, una combinación de propiedades ventajosas de polímeros reabsorbibles naturales y el material bioactivo en nanoescala que parece ser más relevante para su uso en defectos óseos.

PALABRAS CLAVE: Biomateriales, reparación ósea, ingeniería de tejidos, odontología.

\section{REFERENCES}

Al Ruhaimi, K. A. Bone graft substitutes: a comparative qualitative histologic review of current osteoconductive grafting materials. Int. J. Oral Maxillofac. Implants, 16(1):105-14, 2001.

Becker, W.; Clokie, C.; Sennerby, L.; Urist, M. R. \& Becker, B. E. Histologic findings after implantation and evaluation of different grafting materials and titanium micro screws into extraction sockets: case reports. J. Periodontol., 69(4):414-21, 1998.

Boccaccini, A. R.; Notingher, I.; Maquet, V. \& Jérôme, R. Bioresorbable and bioactive composite materials based on polylactide foams filled with and coated by Bioglass particles for tissue engineering applications. J. Mater. Sci. Mater. Med., 14(5):44350, 2003.

Bosetti, M. \& Cannas, M. The effect of bioactive glasses on bone marrow stromal cells differentiation. Biomaterials, 26(18):3873-9, 2005.

Cai, X.; Tong, H.; Shen, X.; Chen, W.; Yan, J. \& Hu, J. Preparation and characterization of homogeneous chitosan-polylactic acid/hydroxyapatite nanocomposite for bone tissue engineering and evaluation of its mechanical properties. Acta Biomater., 5(7):2693-703, 2009.
Cancian, D. C.; Hochuli-Vieira, E.; Marcantonio, R. A. \& Marcantonio, E. Jr. Use of BioGran and Calcitite in bone defects: histologic study in monkeys (Cebus apella). Int. J. Oral Maxillofac. Implants, 14(6):85964, 1999.

Cordioli, G.; Mazzocco, C.; Schepers, E.; Brugnolo, E. \& Majzoub, Z. Maxillary sinus floor augmentation using bioactive glass granules and autogenous bone with simultaneous implant placement. Clinical and histological findings. Clin. Oral Implants Res., 12(3):270-8, 2001.

Caria, P. H.; Kawachi, E. Y.; Bertran, C. A. \& Camilli, J. A. Biological assessment of porous-implant hydroxyapatite combined with periosteal grafting in maxillary defects. J. Oral Maxillofac .Surg., 65(5):847-54, 2007.

Carmagnola, D.; Adriaens, P. \& Berglundh, T. Healing of human extraction sockets filled with Bio-Oss. Clin. Oral Implants Res., 14(2):137-43, 2003.

Fialho, S. L.; Rego, M. G. B.; Cardillo, J. A.; Siqueira, R. C.; Jorge, R. \& Cunha Júnior, A. S. Implantes biodegradáveis destinados à administração intra-ocular. Arq. Bras. Oftalmol., 66(6):891-6, 2003.

Freire, A. R.; Rossi, A. C.; Queiroz, T. P.; Gulinelli, J. L.; Souza, 
F. Á.; Margonar, R.; Garcia-Júnior, I. R.; Hochuli-Vieira, E. \& Okamoto, R. Histometric analysis of bone repair in bone-implant interface using a polylactic/polyglycolic acid copolymer associated with implants in rabbit tibia. J. Oral Implantol., 38:449-57, 2012.

Fujii, E.; Ohkubo, M.; Tsuru, K.; Hayakawa, S.; Osaka, A.; Kawabata, K.; Bonhomme, C. \& Babonneau, F. Selective protein adsorption property and characterization of nanocrystalline zinc-containing hydroxyapatite. Acta Biomater., 2(1):69-74, 2006.

Gatti, A. M. \& Zaffe, D. Short-term behaviour of two similar active glasses used as granules in the repair of bone defects. Biomaterials, 12(5):497-504, 1991.

Gatti, A. M.; Simonetti, L. A.; Monari, E.; Guidi, S. \& Greenspan, D. Bone augmentation with bioactive glass in three cases of dental implant placement. J. Biomater. Appl., 20(4):325-39, 2006.

Giannoudis, P. V.; Einhorn, T. A.; Schmidmaier, G. \& Marsh, D. The diamond concept--open questions. Injury, 39 (Suppl. 2):S5-8, 2008.

Hämmerle, C. H. \& Lang, N. P. Single stage surgery combining transmucosal implant placement with guided bone regeneration and bioresorbable materials. Clin. Oral Implants Res., 12(1):9-18, 2001.

Hench, L. L. The story of Bioglass. J. Mater. Sci: Mater. Med., 17(11):967-78, 2006.

Holy, C. E.; Fialkov, J. A.; Davies, J. E. \& Shoichet, M. S. Use of a biomimetic strategy to engineer bone. J Biomed. Mater. Res. A, 65(4):447-53, 2003.

Imbronito, A. V.; Scarano, A.; Orsini, G.; Piatelli, A. \& AranaChavez, V. E. Ultrastructure of bone healing in defects grafted with a copolymer of polylactic/polyglycolic acids. J. Biomed. Mater. Res., 74(2):215-21, 2005.

Ishida, H.; Tamai, S.; Yajima, H.; Inoue, K.; Ohgushi, H. \& Dohi, Y. Histologic and biochemical analysis of osteogenic capacity of vascularized periosteum. Plast. Reconstr. Surg., 97(3):512-8, 1996.

Jayabalan, M.; Shalumon, K. T.; Mitha, M. K.; Ganesan, K. \& Epple, M. Effect of hydroxyapatite on the biodegradation and biomechanical stability of polyester nanocomposites for orthopaedic applications. Acta Biomater., 6(3):76375, 2010.

Jayakumar, R.; Prabaharan, M.; Nair, S. V. \& Tamura, H. Novel chitin and chitosan nanofibers in biomedical applications. Biotechnol. Adv., 28(1):142-50, 2010.

Jayaraman, K.; Kotaki, M.; Zhang, Y.; Mo, X. \& Ramakrishna,
S. Recent advances in polymer nanofibers. J. Nanosci. Nanotechnol., 4(1-2):52-65, 2004.

Jones, J. R.; Ehrenfried, L. M. \& Hench, L. L. Optimising bioactive glass scaffolds for bone tissue engineering. Biomaterials, 27(7):964-73, 2006.

Kashiwazaki, H.; Kishiya, Y.; Matsuda, A.; Yamaguchi, K.; lizuka, T.; Tanaka, J. \& Inoue, N. Fabrication of porous chitosan/hydroxyapatite nanocomposites: their mechanical and biological properties. Biomed. Mater. Eng., 19(2-3):133-40, 2009.

Kiely, K. D.; Wendfeldt, K. S.; Johnson, B. E.; Haskell, B. S. \& Edwards, R. C. One-year postoperative stability of LeFort I osteotomies with biodegradable fixation: a retrospective analysis of skeletal relapse. Am. J. Orthod. Dentofacial Orthop., 130(3):310-6, 2006.

Koleganova, V. A.; Bernier, S. M.; Dixon, S. J. \& Rizkalla, A. $\mathrm{S}$. Bioactive glass/polymer composite materials with mechanical properties matching those of cortical bone. J. Biomed. Mater. Res. A, 77(3):572-9, 2006.

Kuru, B.; Yilmaz, S.; Argin, K. \& Noyan, U. Enamel matrix derivative alone or in combination with a bioactive glass in wide intrabony defects. Clin. Oral Investig., 10(3):227-34, 2006.

Lang, N. P.; Araújo, M. \& Karring, T. Alveolar bone formation. In: Lindhe, J. Clinical Periodontology and Implant Dentistry. 3rd ed. Copenhagen, Blackell Munksgard, 2003. pp.866-92.

Leach, J. K.; Kaigler, D.; Wang, Z.; Krebsbach, P. H. \& Mooney, D. J. Coating of VEGF-releasing scaffolds with bioactive glass for angiogenesis and bone regeneration. Biomaterials, 27(17):3249-55, 2006.

Lu, H. H.; El-Amin, S. F.; Scott, K. D. \& Laurencin, C. T. Threedimensional, bioactive, biodegradable, polymer-bioactive glass composite scaffolds with improved mechanical properties support collagen synthesis and mineralization of human osteoblast-like cells in vitro. J. Biomed. Mater. Res. A, 64(3):465-74, 2003.

Mano, J. F.; Silva, G. A.; Azevedo, H. S.; Malafaya, P. B.; Sousa, R. A.; Silva, S. S.; Boesel, L. F.; Oliveira, J. M.; Santos, T. C. Marques, A. P.; Neves, N. M. \& Reis, R. L. Natural origin biodegradable systems in tissue engineering and regenerative medicine: present status and some moving trends. J. R. Soc. Interface, 4(17):9991030, 2007.

Mindea, S. A.; Shih, P. \& Song, J. K. Recombinant human bone morphogenetic protein-2-induced radiculitis in elective minimally invasive transforaminal lumbar interbody fusions: a series review. Spine (Phila. Pa. 1976), 34(14):1480-4, 2009. 
Moon, H. J.; Kim, K. N.; Kim, K. M.; Choi, S. H.; Kim, C. K.; Kim, K. D.; LeGeros, R. Z. \& Lee, Y. K. Effect of calcium phosphate glass on bone formation in calvarial defects of Sprague-Dawley rats. J. Mater. Sci. Mater. Med., 17(9):807-13, 2006.

Moreira-Gonzalez, A.; Lobocki, C.; Barakat, K.; Andrus, L.; Bradford, M.; Gilsdorf, M. \& Jackson, I. T. Evaluation of $45 S 5$ bioactive glass combined as a bone substitute in the reconstruction of critical size calvarial defects in rabbits. J. Craniofac. Surg., 16(1):63-70, 2005.

Nair, Pn. Pn. \& Schug, J. Observations on healing of human tooth extraction sockets implanted with bioabsorbable polylactic-polyglycolic acids (PLGA) copolymer root replicas: a clinical, radiographic, and histologic follow-up report of 8 cases. Oral Surg. Oral Med. Oral Pathol. Oral Radiol. Endod., 97(4):559-69, 2004.

Oonishi, H.; Hench, L. L.; Wilson, J.; Sugihara, F.; Tsuji, E.; Matsuura, M.; Kin, S.; Yamamoto, T. \& Mizokawa, S. Quantitative comparison of bone growth behavior in granules of Bioglass, A-W glass-ceramic, and hydroxyapatite. J. Biomed. Mater. Res., 51(1):37-46, 2000.

Osathanon, T.; Linnes, M. L.; Rajachar, R. M.; Ratner, B. D.; Somerman, M. J. \& Giacheli, C. M. Microporous nanofibrous fibrin-based scaffolds for bone tissue engineering. Biomaterials, 29(30):4091-9, 2008.

Pellegrini, G.; Seol, Y. J.; Gruber, R. \& Giannobile, W. V. Preclinical models for oral and periodontal reconstructive therapies. J. Dent. Res., 88(12):1065-76, 2009.

Radin, S.; Reilly, G.; Bhargave, G.; Leboy, P. S. \& Ducheyne, $P$. Osteogenic effects of bioactive glass on bone marrow stromal cells. J. Biomed. Mater. Res. A, 73(1):21-9, 2005.

Rimondini, L.; Nicoli-Aldini, N.; Fini, M.; Guzzardella, G.; Tschon, M. \& Giardino, R. In vivo experimental study on bone regeneration in critical bone defects using an injectable biodegradable PLA/PGA copolymer. Oral Surg. Oral Med. Oral Pathol. Oral Radiol. Endod., 99(2):14854, 2005.

Rosen, H. M. Porous, block hydroxyapatite as an interpositional bone graft substitute in orthognathic surgery. Plast. Reconstr. Surg., 83(6):985-90, 1989.

Saito, N.; Okada, T.; Horiuchi, H.; Ota, H.; Takahashi, J.; Murakami, N.; Nawata, M.; Kojima, S.; Nozaki, K. \& Takaoka, K. Local bone formation by injection of recombinant human bone morphogenetic protein-2 contained in polymer carriers. Bone, 32(4):381-6, 2003.

Scheller, E. L. \& Krebsbach, P. H. Gene therapy: design and prospects for craniofacial regeneration. J. Dent. Res., 88(7):585-96, 2009.
Schepers, E.; de Clercq, M.; Ducheyne, P. \& Kempeneers, $\mathrm{R}$. Bioactive glass particulate material as a filler for bone lesions. J. Oral Rehabil., 18(5):439-52, 1991.

Schepers, E. J.; Ducheyne, P.; Barbier, L. \& Schepers, S. Bioactive glass particles of narrow size range: a new material for the repair of bone defects. Implant Dent., 2(3):151-6, 1993.

Semino, C. E. Self-assembling peptides: from bio-inspired materials to bone regeneration. J. Dent. Res., 87(7):60616, 2008.

Serino, G.; Biancu, S.; lezzi, G. \& Piatelli, A. Ridge preservation following tooth extraction using a polylactide and polyglycolide sponge as space filler: a clinical and histological study in humans. Clin. Oral Implants Res., 14(5):651-8, 2003.

Sill, T. J. \& von Recum, H. A. Electrospinning: applications in drug delivery and tissue engineering. Biomaterials, 29(13):1989-2006, 2008.

Smith, L. A. \& Ma, P. X. Nano-fibrous scaffolds for tissue engineering. Colloids Surf. B Biointerfaces, 39(3):12531, 2004.

Stavropoulos, A.; Kostopoulos, L.; Nyengaard, J. R. \& Karring, T. Deproteinized bovine bone (Bio-Oss) and bioactive glass (Biogran) arrest bone formation when used as an adjunct to guided tissue regeneration (GTR): an experimental study in the rat. J. Clin. Periodontol., 30(7):63643, 2003.

Tadjoedin, E. S.; de Lange, G. L.; Holzmann, P. J.; Kulper, L. \& Burger, E. H. Histological observations on biopsies harvested following sinus floor elevation using a bioactive glass material of narrow size range. Clin. Oral Implants Res., 11(4):334-44, 2000.

Tadjoedin, E. S.; de Lange, G. L.; Lyaruu, D. M.; Kuiper, L. \& Burger, E. H. High concentrations of bioactive glass material (BioGran) vs. autogenous bone for sinus floor elevation. Clin. Oral Implants Res., 13(4):428-36, 2002.

Talal, A.; Waheed, N.; Al-Masri, M.; McKay, I. J.; Tanner, K. E. \& Hughes, F. J. Absorption and release of protein from hydroxyapatite-polylactic acid (HA-PLA) membranes. J. Dent., 37(11):820-6, 2009.

Tang, X. J.; Gui, L. \& Lü, X. Y. Hard tissue compatibility of natural hydroxyapatite/chitosan composite. Biomed. Mater., 3(4):044115, 2008.

Teófilo, J. M.; Brentegani, L. G. \& Lamano-Carvalho, T. L. Bone healing in osteoporotic female rats following intraalveolar grafting of bioactive glass. Arch. Oral Biol., 49(9):755-62, 2004. 
Villaça, J. H.; Novaes, A. B. Jr.; Souza, S. L.; Taba, M. Jr.; Molina, G. O. \& Carvalho, T. L. Bioactive glass efficacy in the periodontal healing of intrabony defects in monkeys. Braz. Dent. J., 16(1):67-74, 2005.

Wheeler, D. L.; Stokes, K. E.; Hoellrich, R. G.; Chamberland, D. L. \& McLoughlin, S. W. Effect of bioactive glass particle size on osseous regeneration of cancellous defects. J. Biomed. Mater. Res., 41(4):527-33, 1998.

Woo, K. M.; Seo, J.; Zhang, R. \& Ma, P. X. Suppression of apoptosis by enhanced protein adsorption on polymer/ hydroxyapatite composite scaffolds. Biomaterials, 28(16):2622-30, 2007.

Wu, Y. C.; Shaw, S. Y.; Lin, H. R.; Lee, T. M. \& Yang, C. Y. Bone tissue engineering evaluation based on rat calvaria stromal cells cultured on modified PLGA scaffolds. Biomaterials, 27(6):896-904, 2006.

Yamaguchi, A.; Komori, T. \& Suda, T. Regulation of osteoblast differentiation mediated by bone morphogenetic proteins, hedgehogs, and Cbfa1. Endocr. Rev., 21(4):393-411, 2000.

Yao, J.; Radin, S.; S. Leboy, P. \& Ducheyne, P. The effect of bioactive glass content on synthesis and bioactivity of composite poly (lactic-co-glycolic acid)/bioactive glass substrate for tissue engineering. Biomaterials, 26(14):1935-43, 2005.

Yoshida, A.; Miyazaki, T.; Ashizuka, M. \& Ishida, E. Bioactivity and mechanical properties of cellulose/carbonate hydroxyapatite composites prepared in situ through mechanochemical reaction. J. Biomater. Appl., 21(2):17994, 2006.

Zaky, S. H. \& Cancedda, R. Engineering craniofacial structures: facing the challenge. J. Dent. Res., 88(12):1077-91, 2009.

Zhang, Y.; Venugopal, J. R.; El-Turki, A.; Ramakrishna, S.; Su, B. \& Lim, C. T. Electrospun biomimetic nanocomposite nanofibers of hydroxyapatite/chitosan for bone tissue engineering. Biomaterials, 29(32):4314-22, 2008.
Correspondence to:

Ana Cláudia Rossi

Department of Morphology, Anatomy area

Piracicaba Dental School

State University of Campinas - UNICAMP.

Av. Limeira, 901, Postal Box \#52

13414-903

Piracicaba

São Paulo

BRAZIL

Email: anaanatomia@gmail.com

Received: 25-02-2014

Accepted: 06-06-2014 